\title{
Is a Paradigm Shift Occurring in Brief Psychological Treatments?
}

\author{
Isaac Marks \\ Institute of Psychiatry, London, UK
}

The value of several brief psychological treatments has long been shown for anxiety and depressive disorders. Overlap in their various components, however, made it unclear what aspects of the treatments improved patients. For example, cognitive behaviour therapy (CBT) combines both the cognitive and behavioural components. In the last few years, a growing number of randomised controlled trials (RCTs) in Europe and North America have examined behaviour therapy and cognitive therapy on their own; these RCTs found that each therapy on its own was comparably effective for a range of both anxiety and depressive disorders. Other approaches, too, have been helpful.

In RCTs in anxiety disorders, behaviour therapy (exposure) alone and cognitive therapy alone obtained similar improvements in obsessive-compulsive disorder [1], in posttraumatic stress disorder [2,3] and in hypochondriasis [4]. Blood phobia improved lastingly when sufferers learned a physiological coping response - muscle tension (without exposure and without cognitive therapy) - to prevent the fainting that is the hallmark of blood phobia; improvement was even greater with muscle tension than with exposure [5]. Generalised anxiety disorder improved with a problem-solving approach that contained minimal exposure or cognitive components [6].

In a large RCT in depressive disorder, behavioural activation alone led to as much improvement up to 6 months follow-up as did attenuated cognitive therapy which taught the modification of automatic thoughts plus behavioural activation, or full cognitive therapy which also added a focus on core schema [7]. Other RCTs in depressive disorder found value in a problem-solving approach that was not cognitive and did not promote behavioural activation [8]. A multicentre NIMH study found similar improvements in mild-to-moderate depression from interpersonal therapy, from cognitive therapy and from imipramine [9].

It is not the case that all treatments get prizes. Some do not. In RCTs, relaxation, anti-exposure and standard primary care treatment were less useful than the above effective approaches for anxiety disorders, and drug-placebo and standard primary care were less helpful for depression. The superior results of several brief treatments thus cannot all be accounted for by general non-specific effects.

Such results have important theoretical implications. Prevailing paradigms of therapeutic mechanisms will have to change. In anxiety disorders, it is now clear that habituation from systematic exposure is sufficient, but not necessary to reduce fear. The package that is called cognitive therapy can also reduce fear, but there is doubt whether it usually works by cognitive restructuring. Specific physiological coping skills and also problem-solving approaches have a role to play in certain disorders. It is not necessary to try to change cognitions to improve mood reliably, e.g. depression improves with non-cogni-

\begin{tabular}{ll}
\hline KARGER & (c) 1999 S. Karger AG, Basel \\
Fax +4161306 1234 & $0033-3190 / 99 / 0684-0169 \$ 17.50 / 0$ \\
$\begin{array}{l}\text { E-Mail karger@karger.ch } \\
\text { www.karger.com }\end{array}$ & Accessible online at: \\
http://BioMedNet.com/karger
\end{tabular}

Isaac Marks, MD

Institute of Psychiatry

London SE5 8AF(UK) 
tive therapies such as behavioural activation, interpersonal therapy and problem-solving.

The weakening of recent paradigms by the ferment of new results is welcome, but it is unclear what will replace them. A major research task ahead is the unravelling of how many roads there are to the Rome of improving anxiety and depression. Some treatments may work by converging on similar paths, others by different ones. IT seems unlikely that all will work by just one final common pathway.

\section{References}

1 Van Oppen P, De Haan E, Van Balkom AJLM, Spinhoven P, Hoogduin K, Van Dyck R: Cognitive therapy and exposure in vivo in the treatment of obsessive compulsive disorder. Behav Res Ther 1995;33:379-390.

2 Marks I, Lovell K, Noshirvani H, Livanou M, Thrasher S: Treatment of posttraumatic stress disorder by exposure and/or cognitive restructuring. Arch Gen Psychiatry 1998;55:317325.

3 Tarrier N, Pilgrim H, Sommerfield C, Faragher B, Reynolds M, Graham E, Barrowclough C: Randomized trial of cognitive therapy and imaginal exposure in the treatment of chronic PTSD. J Consult Clin Psychol, in press.
4 Bouman T, Visser S: Cognitive and behavioural treatment of hypochondriasis. Psychother Psychosom 1998;67:214-221.

5 Ost L, Fellenjus J, Sterner U: Applied tension, exposure in vivo and tension-only in the treatment of blood phobia. Behav Res Ther 1991; 29:561-574.

6 Bowman D, Scogin F, Floyd M, Patton E, Gist L: Efficacy of self-examination therapy in the treatment of generalized anxiety disorder. J Consult Clin Psychol 1997;44:267-273.

7 Jacobson NS, Dobson KS, Truax PA, Addis ME, Koerner K, Gollan JK, Gortner E, Prince SE: A component analysis of cognitive-behavioral treatment for depression. J Consult Clin Psychol 1996;64:295-304.
8 Mynors-Wallis LM, Gath DH, Lloyd-Thomas AR, Tomlinson D: Randomised controlled trial comparing problem solving treatment with amitriptyline and placebo for major depression in primary care. BMJ 1995;310:441445.

9 Elkin I, Shea T, Watkins JT, Imber SP, Sotsky SM, Collins JF, Glass DR, Pilkonis PA, Leber WR, Docherty JP, Fiester SJ, Parloff MB: National Institute of Mental Health Treatment of Depression Collaborative Research Program. Arch Gen Psychiatry 1989;46:971-982. 